\title{
Hypoallergenic infant formula lacks transforming growth factor beta activity and has a lower anti-inflammatory activity than regular infant formula
}

\author{
Layla Panahipour, ${ }^{1} \odot$ Amirali Abooneghab Tabatabaei, ${ }^{1}$ (๑) and Reinhard Gruber ${ }^{1,2,3 *}$ (이 \\ ${ }^{1}$ Department of Oral Biology, Medical University of Vienna, Sensengasse 2a, 1090 Vienna, Austria \\ ${ }^{2}$ Department of Periodontology, School of Dental Medicine, University of Bern, Freiburgstrasse 7, 3010 Bern, Switzerland \\ ${ }^{3}$ Austrian Cluster for Tissue Regeneration, Donaueschingenstraße 13, 1200 Vienna, Austria
}

\section{ABSTRACT}

Hypoallergenic formulas are recommended for infants who are not breastfed and cannot tolerate cow milk formulas due to allergy. These formulas are hydrolyzed to break down larger protein chains into shorter, easy-to-digest, and potentially less allergenic proteins. Hydrolysis, however, possibly occurs at the expense of the transforming growth factor beta (TGF- $\beta$ ) and anti-inflammatory activity that is inherent in regular formula. Our objective was to determine the TGF- $\beta$ and the anti-inflammatory activity of commercially available hypoallergenic and regular formulas. Human gingival fibroblasts were incubated with reconstituted formulas followed by detection of TGF- $\beta$ target genes and activation of Smad2/3 signaling. Gingival fibroblasts and the oral squamous cell carcinoma cell line HSC-2 were also exposed to formulas before adding interleukin (IL) $1 \beta$ and tumor necrosis factor (TNF) $\alpha$ to provoke expression of pro-inflammatory cytokines. For murine bone marrow-derived macrophages, pro-inflammatory cytokine expression was stimulated with saliva. Changes in p65 nuclear translocation and phosphorylation of smad3 and p38 were analyzed by immunostaining. Our study demonstrated that regular formula, but not hypoallergenic formula, enhanced the expression of TGF- $\beta$ target genes IL11, PRG4, and $N_{4} 4$ in gingival fibroblasts. Hypoallergenic formulas also failed to initiate nuclear translocation of $\operatorname{Smad} 2 / 3$ and phosphorylation of Smad3. Moreover, regular formulas were more potent than hypoallergenic formulas in reducing the expression of pro-inflammatory cytokines in gingival fibroblasts, HSC-2 epithelial cells, and murine bone marrow macrophages. Hypoallergenic and regular formulas had a similar capacity to reduce p65 nuclear translocation and phosphorylation of p38 in fibroblasts. These findings suggest that hypoallergenic formulas lack in vitro TGF- $\beta$ activity and have a lower

Received December 16, 2019.

Accepted March 27, 2020.

*Corresponding author: reinhard.gruber@meduniwien.ac.at anti-inflammatory activity compared with regular formulas.

Key words: hypoallergenic formula, regular formula, TGF- $\beta$ activity, anti-inflammatory activity

\section{INTRODUCTION}

Breastfeeding up to $2 \mathrm{yr}$ of age is recognized as the standard for infant feeding, and medical contraindications to breastfeeding are rare (Section on, 2012). Nonetheless, breastfeeding prevalence remains low in Europe; only an estimated $25 \%$ of infants were exclusively breastfed for the first 6 mo (Cattaneo et al., 2010; Bagci Bosi et al., 2016). Thus, formulas are increasingly used as substitutes for breast milk. Formulas are mainly categorized into regular and specialized formulas. The most common formula is regular infant formula composed of spray-dried cow milk (Green Corkins and Shurley, 2016). Specialized formulas are designed to satisfy the nutritional requirements of infants with specific medical conditions, including allergies. In the last few years, specialized formula sales have increased significantly (Annunziata and Vecchio, 2011). For example, in 2003 in Italy, hydrolyzed protein formula had a $21.1 \%$ market share (Frongia and Bellomo, 2005). These numbers seem high, considering that 2 to $3 \%$ of the most common allergens in children are associated with the intake of cow milk (Sackesen et al., 2011; Sicherer and Sampson, 2014). In a prospective cohort study, 54 infants with IgE raised against cow milk allergy were identified from a population of 13,019 children followed from birth (Elizur et al., 2012). Even though the diagnosis is challenging (Bellini et al., 2014), cow milk allergy is the most common food allergy in newborns, and is induced by undigested milk proteins (Sackesen et al., 2011; Sicherer and Sampson, 2014). Formulas are widely used to substitute for breastfeeding, with an increasing use of hydrolyzed protein to make hypoallergenic infant formulas developed for infants with allergy to milk proteins.

Hypoallergenic formulas come in 3 main varieties: partially hydrolyzed, extensively hydrolyzed, and free 
amino acid-based. The more extensively hydrolyzed the formula is, the fewer potentially allergenic compounds remain, and the better an allergic infant may tolerate it. The American Academy of Pediatrics (2012) recommends using extensively hypoallergenic formulas in babies and children with food allergies. Caseins, $\beta$-lactoglobulin, and $\alpha$-lactalbumin are considered to be the major milk allergens (Monaci et al., 2006). Therefore, the partial or extensive cleavage of cow milk proteins achieved by peptidases is one of the most effective methods of reducing allergic reactions to these proteins (Bu et al., 2013). According to the German Infant Nutritional Intervention Study (von Berg et al., 2017), when using hypoallergenic formula, the incidence of atopic eczema before school age is reduced to between $26 \%$ and $45 \%$ compared with regular formula (von Berg et al., 2017). A beneficial effect of hypoallergenic formula on the respiratory symptoms of asthma and rhinoconjunctivitis, however, was not shown (von Berg et al., 2017). Thus, there is at least limited clinical evidence that prolonged feeding with a hypoallergenic formula compared with a regular formula reduces infant and childhood allergy and infant cow milk allergy (Osborn and Sinn, 2006), but the issue remains controversial (Osborn et al., 2018). However, the processing of cow milk may also reduce the beneficial value of the bioactive components of the milk that are supposed to reduce allergies and exert anti-inflammatory activity.

Milk is a rich source of transforming growth factor beta (TGF- $\boldsymbol{\beta}$ ), with the most abundant isoforms being TGF- $\beta 2$ and TGF- $\beta 1$ (Sitarik et al., 2017). There is evidence that milk can ameliorate tissue damage and mortality in dextran sodium sulfate colitis and lipopolysaccharide-induced endotoxemia murine models, with this effect being attributed to TGF- $\beta$ signaling (Ozawa et al., 2009). Cow milk or the recombinant growth factor was shown to increase plasma TGF- $\beta$ concentrations (Ando et al., 2007; Ozawa et al., 2009). Additionally, the allergy-protective effect of dietary acidic oligosaccharides is mediated by TGF- $\beta$ in mice with cow milk allergy (Kerperien et al., 2018). Cow milk had significant beneficial effects on skin wound healing in a preclinical model (Hemmati et al., 2018). Even though oral mucosal healing was considered the ideal system of wound resolution (Iglesias-Bartolome et al., 2018), oral mucositis is a frequent and severe complication of chemotherapy in children (Cheng et al., 2008) and adults with cancer (Lalla et al., 2014). Considering that milk comes into contact with the oral mucosa, we have recently confirmed TGF- $\beta$ and antiinflammatory activity of milk in bioassays representing oral fibroblast and oral epithelial cells (Panahipour et al., 2018b, 2019) and macrophages that are highly abundant in the oral mucosa (Panahipour et al., 2018a). We further confirmed the anti-inflammatory activity of regular formula, but not the respective TGF- $\beta$ activity (Panahipour et al., 2019). More importantly, we have not included hypoallergenic formulas produced by hydrolysis in our testing of TGF- $\beta$ and anti-inflammatory activity.

Enzymatic hydrolysis may cleave, and thereby inactivate, proteins with a biological function, including TGF- $\beta$ and possibly other factors responsible for the anti-inflammatory activity of milk. The immunogenicity and allergenicity of 2 milk hydrolysates were examined using intraperitoneal dosing on preclinical models (Bøgh et al., 2015). However, there is no support for this hypothesis. Additionally, hypoallergenic formula has not been tested for its TGF- $\beta$ and antiinflammatory activity in bioassays. Recently, Holvoet et al. (2019) provided the first insights into the role of TGF- $\beta$ activity in hypoallergenic formulas. They supplemented hydrolyzed formulas with a whey protein isolate containing TGF- $\beta$ obtained from skimmed cow milk. In vitro, whey protein isolates inhibited cell proliferation of Mv1Lu cells via TGF- $\beta 2$ activity, whereas partially hypoallergenic formula showed no effect (Holvoet et al., 2019). In ovalbumin-tolerized mice, the TGF- $\beta$-enriched formula reduced the allergic reactions indicated by the total $\mathrm{IgE}$ and mucosal mast cell protease-1 (mMCP-1) levels, but not in a regular hydrolyzed formula (Holvoet et al., 2019). The findings of Holvoet et al. (2019) provide the first data that show hydrolyzed formulas are devoid of TGF- $\beta$.

The aim of the present study was to determine the TGF- $\beta$ activity and anti-inflammatory activity of commercially available hypoallergenic and regular formulas in vitro.

\section{MATERIALS AND METHODS}

\section{Hypoallergenic and Regular Formulas}

Three different manufacturers' batches of regular (R1, R2, and R3) and hypoallergenic (H1, H2, H3) formulas were reconstituted in serum-free medium: Dulbecco's modified Eagle medium (DMEM) for fibroblast experiments and alpha minimum essential medium ( $\mathbf{\alpha M E M})$ for primary macrophage experiments, to reach a $20 \%$ (wt/vol) stock solution that was further diluted to a working concentration of $1 \%$. The samples were always prepared freshly for each experiment. Pooled infant formula samples from the 3 batches were designated $\mathbf{R F}$ (regular formula) and HAF (hypoallergenic formula). Our untreated control (wo) was serum-free medium only. 
Gingival Fibroblasts and HSC-2 Cells: Basic Experimental Design

Human gingival fibroblasts were prepared from explant cultures from 3 independent donors after approval of the Ethics Committee of the Medical University of Vienna (EC No. 631/2007). Cells were cultured in a humidified atmosphere at $37^{\circ} \mathrm{C}, 5 \% \mathrm{CO}_{2}$, and $95 \%$ humidity in growth medium consisting of DMEM, $10 \%$ fetal calf serum, and $1 \%$ of 10,000 units penicillin and $10 \mathrm{mg}$ of streptomycin/mL (Sigma, St Louis, MO). Cells were plated in growth medium at 30,000 cells/ $\mathrm{cm}^{2}$ into 12-well plates. The following day, cells were incubated with $1 \%$ formula in serum-free DMEM for the analysis of TGF- $\beta$ target genes IL11, NOX 4 , and $P R G 4$. The inhibitor for the TGF- $\beta$ receptor type 1 kinase, SB431542 (Calbiochem, Merck, Billerica, MA) was used at $10 \mu \mathrm{M}$. In indicated experiments, $1 \% \mathrm{RF}$ was incubated with papain from papaya latex (P3125, Sigma, St Louis, MO) at $5 \mu \mathrm{g} / \mathrm{mL}$, equivalent to 0.1 unit $/ \mathrm{mL}$, for $24 \mathrm{~h}$ at $37^{\circ} \mathrm{C}$. Papain was inactivated by incubation at $80^{\circ} \mathrm{C}$ for $1 \mathrm{~h}$ before cell exposure. To identify anti-inflammatory effects, cells were exposed to $1 \%$ of the pooled formulas in serum-free DMEM for $1 \mathrm{~h}$ following inflammation provoked by human IL1 $\beta$ and TNF $\alpha$ (ProSpec-Tany TechnoGene Ltd., Rehovot, Israel), both at $5 \mathrm{ng} / \mathrm{mL}$ in the serum-free medium. To verify the anti-inflammatory effects, experiments were repeated with the oral squamous cell carcinoma cell line HSC-2, originally obtained from Health Science Research Resources Bank (Sennan, Japan), provided by Professor Rausch-Fan, Department of Periodontology, Medical University of Vienna, Austria. After 24 h, gene expression analysis was performed.

\section{Murine Bone Marrow-Derived Macrophages}

Bone marrow cells were collected from the femurs and tibias of Balb/c mice aged 6 to 8 wk old. Bone marrow cells were seeded at $1 \times 10^{6}$ cells $/ \mathrm{cm}^{2}$ into 24 well plates and grown for $7 \mathrm{~d}$ in $\alpha \mathrm{MEM}$ supplemented with $10 \%$ fetal bovine serum, antibiotics (all from Invitrogen, Grand Island, NY) and $30 \mathrm{ng} / \mathrm{mL}$ macrophage colony stimulating factor (Prospec, Ness-Ziona, Israel) under standard conditions at $37^{\circ} \mathrm{C}, 5 \% \mathrm{CO}_{2}$, and $95 \%$ humidity. Primary macrophages were exposed to $1 \%$ formula for $1 \mathrm{~h}$ before being exposed to $5 \%$ saliva for $24 \mathrm{~h}$ based on our established protocol (Pourgonabadi et al., 2017).

\section{Saliva Preparation}

We have recently shown that saliva provokes a toll-like receptor 4 (TLR4)-dependent inflammatory response in macrophages (Pourgonabadi et al., 2017). Following the same procedure, whole human saliva was collected from the authors (L.P., R.G.) who are nonsmokers and gave their informed consent. No saliva was used from infants, even though the composition is not exactly the same as that of adult saliva (Manconi et al., 2013; Carvalho et al., 2016). Saliva flow was stimulated by chewing paraffin wax (Ivoclar Vivadent AG, Schaan, Liechtenstein) without eating or drinking for $1 \mathrm{~h}$ before collection. Immediately after collection, saliva was centrifuged at $4,000 \times g$ for $5 \mathrm{~min}$. The saliva supernatant was passed through a filter with a pore diameter of 0.2 $\mu \mathrm{m}$ (Diafil PS, DIA-Nielsen GmbH, Düren, Germany). Saliva was pooled and frozen stocks were prepared. Saliva was used solely to provoke an inflammatory response in macrophages.

\section{Viability Assay}

For viability experiments, gingival fibroblasts were incubated with the aqueous fraction of formulas at the indicated concentrations (0.1-100\%). After $24 \mathrm{~h}$, an MTT (3-[4,5-dimethythiazol-2-yl]-2,5-diphenyltetrazolium bromide; Sigma) solution at a final concentration of $0.5 \mathrm{mg} / \mathrm{mL}$ was added to each well of a microtiter plate (CytoOne, Starlab International, Hamburg, Germany) for $2 \mathrm{~h}$ at $37^{\circ} \mathrm{C}$. The medium was removed and formazan crystals were solubilized with dimethyl sulfoxide. Optical density was normalized to unstimulated control values.

\section{Reverse Transcription Quantitative Real-Time PCR Analysis}

For reverse transcription quantitative real-time PCR (RT-qPCR; Bustin et al., 2009), total RNA was isolated with the ExtractMe total RNA kit (Blirt S.A., Gdańsk, Poland). Reverse transcription was performed with SensiFAST cDNA (Bioline, London, UK). Polymerase chain reaction was performed with the SensiFAST SYBR ROX Kit (Bioline). Intron-spanning primers were designed based on the algorithm of the Universal ProbeLibrary Assay Design Center (www.lifescience .roche.com) and are indicated in Supplemental Table S1 (https://doi.org/10.3168/jds.2019-18067), except for hIL11 (qHsaCEP0049951; Bio-Rad Laboratories Inc., Hercules, CA). Amplification was monitored on the CFX Connect Real-Time PCR Detection System (Bio-Rad Laboratories Inc.). The mRNA levels were calculated by normalizing to the housekeeping gene GAPDH using the $\triangle \triangle \mathrm{Ct}$ method (Schmittgen and Livak, 2008) where $\mathrm{Ct}=$ cycle threshold after exponential expression transformation. 


\section{Immunoassay}

The immunoassay for human IL11 (DY218, R\&D Systems, Minneapolis, MN) was performed with the cell lysates, without supernatant, of gingival fibroblasts exposed to $1 \% \mathrm{RF}$ and HAF after $24 \mathrm{~h}$. The supernatant generated no IL11 signal because the formula dose-dependently blocked the immune reaction. Consistently, supernatants obtained with recombinant TGF- $\beta 1$ at $5 \mathrm{ng} / \mathrm{mL}$, but without formula, caused a robust IL11 signal. The lysates were prepared with $0.1 \%$ Triton $\mathrm{X}$ in distilled water adding protease inhibitors (cOmplete ULTRA Tablets Roche, Mannheim, Germany) and centrifugation. The immunoassay for mouse IL-1ß (DY401, R\&D Systems) was also performed with 24-h lysates of bone marrow macrophages exposed to $1 \% \mathrm{RF}$ and $\mathrm{HAF}$ for $1 \mathrm{~h}$ followed by $5 \%$ saliva.

\section{Immunofluorescence}

To confirm the activation of the TGF- $\beta$ signaling pathway by RF but not HAF, we visualized the nuclear translocation of Smad2/3 by immunostaining. Nuclear translocation of Smad2/3 occurs after their phosphorylation by the TGF- $\beta$-type I receptor kinase, where they regulate transcription of the TGF- $\beta$ target genes (Derynck and Zhang, 2003), including IL11 (Zhang et al., 2015), NOX4 (Bai et al., 2014), and PRG4 (Chavez et al., 2017). To study the ability of formula to modulate the inflammatory response of gingival fibroblasts to IL-1 $\beta$ and TNF- $\alpha$ exposure, p65 staining was performed. The transcription factor p65, also known as

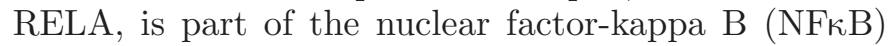
family of transcription factors that play critical roles in inflammation. Inflammation-induced proteosomal degradation of the inhibitor of $\mathrm{NF} \kappa \mathrm{B}$ proteins $(\mathrm{I} \kappa \mathrm{B}$ )

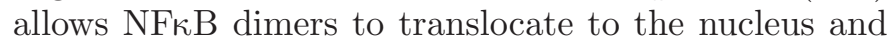
induce transcription of target genes (Oeckinghaus and Ghosh, 2009).

The immunofluorescent analysis of Smad2/3 and p65 were performed in gingival fibroblasts plated on Millicell EZ slides (Merck KGaA, Darmstadt, Germany) at 15,000 cells $/ \mathrm{cm}^{2}$. Serum-starved cells were exposed to $1 \%$ of $\mathrm{RF}$ or $\mathrm{HAF}$ for $30 \mathrm{~min}$. The cells were fixed with $4 \%$ paraformaldehyde, blocked with $1 \%$ BSA, and permeabilized with $0.3 \%$ Triton. We used rabbit

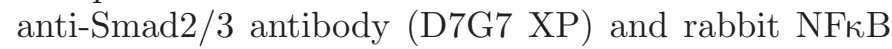
p65 (D14E12 XP, both Cell Signaling Technology, Cambridge, UK) at $4^{\circ} \mathrm{C}$ overnight. For detection, we used the goat anti-rabbit Alexa 488 secondary antibody (CS-4412, 1:1,000, Cell Signaling Technology). Images were captured under a fluorescent microscope with a 455-nm single filter block (Oxion fluorescence, Euromex, Arnheim, the Netherlands).

\section{Western Blot}

To further verify the initiation of TGF- $\beta$ signaling by formulas, we identified the phosphorylation of Smad3 to be a prerequisite for nuclear translocation (Derynck and Zhang, 2003). We also included phosphorylation of p38 mitogen-activated protein (MAP) kinases in our strategy because they are part of a family of serine/ threonine protein kinases that play important roles in cellular responses to external stress signals, including inflammatory cytokines (Kumar et al., 2003).

Gingival fibroblasts were seeded at 50,000 cells/ $\mathrm{cm}^{2}$ into 6 -well plates. The following day, medium was changed to serum-free for overnight incubation. For detection of phosphorylated (p)-Smad3, cells were stimulated for $30 \mathrm{~min}$ with $1 \%$ pooled formula. For p-p38 detection, cells were stimulated for 30 min with $1 \%$ pooled formula before being exposed to IL1 $\beta$ and TNF $\alpha$ for another $30 \mathrm{~min}$. Cell extracts containing SDS buffer with protease and phosphatase inhibitors (cOmplete ULTRA Tablets and PhosSTOP; Roche, Mannheim, Germany) were separated by SDS-PAGE and transferred onto nitrocellulose membranes (Whatman, GE Healthcare, General Electric Company, Fairfield, CT). Membranes were blocked and incubated with antibodies raised against (1) p-smad3 (rabbit; phospho S423 + S425; EP823Y, Abcam, Cambridge, UK), (2) p-p38 MAPK (rabbit; phospho Thr180/Tyr182; D3F9 XP, Cell Signaling Technology), and (3) $\beta$-actin (mouse; C2, SC-8432, Santa Cruz Biotechnology, Dallas, TX) overnight at $4^{\circ} \mathrm{C}$. Following this, the membranes were exposed to the second antibody labeled with horseradish peroxidase (CS-7074, anti-rabbit IgG and CS-7076, anti-mouse IgG, both Cell Signaling Technology), respectively. After exposure to the Clarity Western ECL Substrate (Bio-Rad Laboratories Inc., Hercules, CA), chemiluminescence signals were visualized with the ChemiDoc imaging system (Bio-Rad Laboratories).

\section{Statistical Analysis}

Gene expression was analyzed based on the MannWhitney U test, comparing the mean rank of each treatment group with the mean rank of the untreated control group. For the gene expression indicated in Supplemental Figure S1 (https://doi.org/10.3168/jds .2019-18067), we used the paired $t$-test. The $P$-values are indicated in the respective figures. Statistical analysis was performed using GraphPad software (version 7, GraphPad Inc., San Diego, CA). 

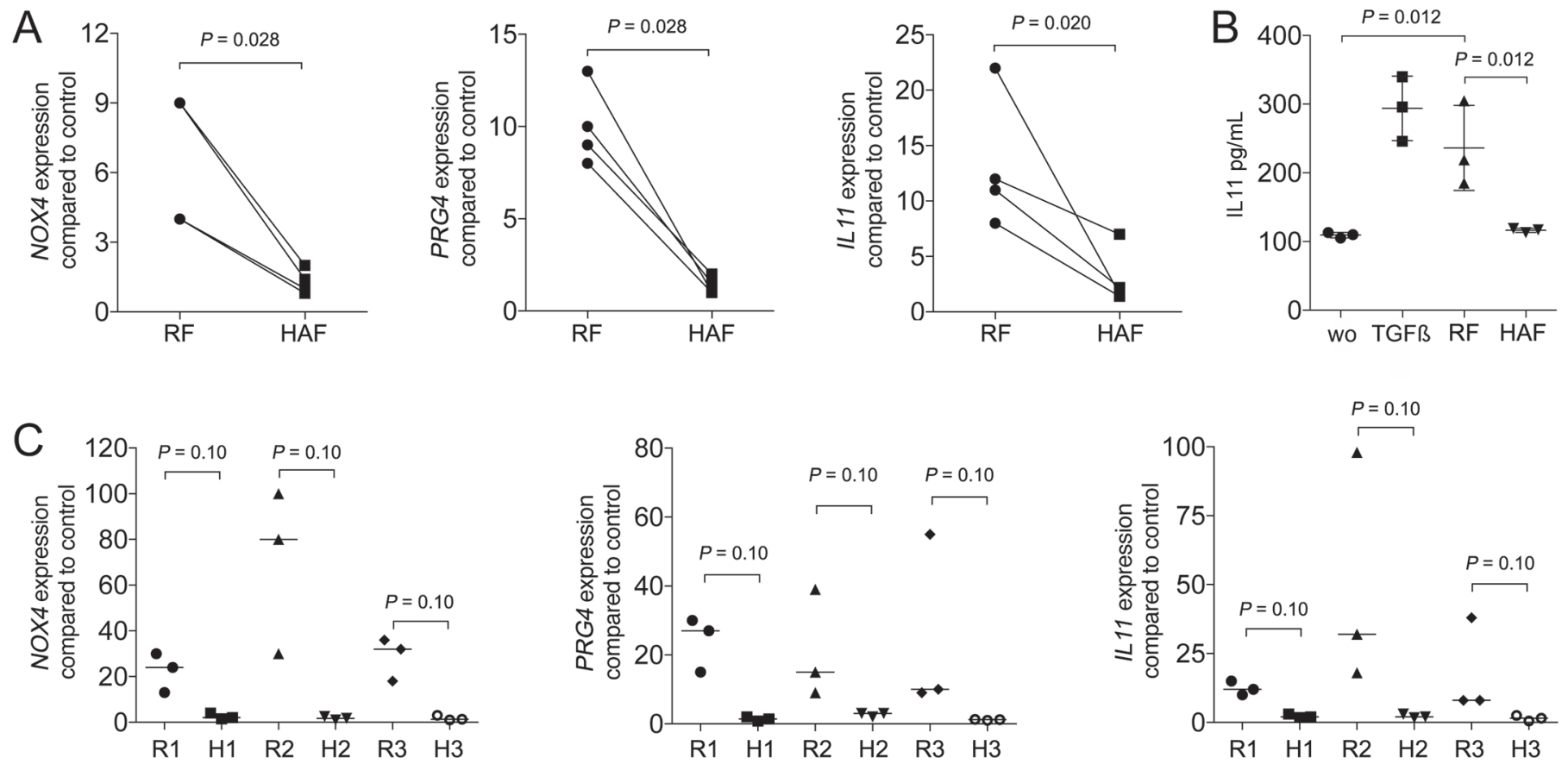

Figure 1. Expression of TGF- $\beta$ target genes in oral fibroblasts. Gingival fibroblasts were exposed to $1 \%$ reconstituted pooled regular infant formula (RF) or hypoallergenic infant formula (HAF) for $24 \mathrm{~h}$ followed by (A) analysis of expression of NOX4, PRG4, and IL11, and (B) an IL11 immunoassay based on cell lysates. (C) Experiments were also performed with reconstituted regular (R) and hypoallergenic (H) formulas from 3 providers (R1, H1, R2, H2, R3, H3). Expression of NOX4, PRG4, and IL11 genes are shown. Data points represent independent experiments. Statistical analysis was based on Mann-Whitney U test.

\section{RESULTS}

\section{Effect of Formulas on TGF- $\beta$ Target Genes}

Human milk is a rich source of TGF- $\beta$ (Zwiebel et al., $1986)$, and we recently reported that cow milk provokes a robust activation of the TGF- $\beta$ target genes in oral gingival fibroblasts (Panahipour et al., 2018b). Considering that formulas are increasingly used as substitutes for breast milk (Cattaneo et al., 2010; Bagci Bosi et al., 2016; Green Corkins and Shurley, 2016), the question arises whether spray drying of cow milk, and processing by hydrolysis in particular, affects the intrinsic TGF- $\beta$ activity. We report here that $1 \%$ reconstituted $\mathrm{RF}$ that did not impair cell viability (data not shown) strongly increased the expression of NOX4, PRG4, and IL11 (by 6.5-, 9.5-, and 11.5-fold, respectively), in median compared with unstimulated control cells (Figure 1A). Compared with the strong increase observed with RF, HAF caused a significant but much weaker increase in expression of TGF- $\beta$ target genes, with $N_{4}, P R G_{4}$, and $I L 11$ by $1.2-(P=0.028), 1.2-(P=0.028)$, and 1.9-fold $(P=0.020)$ in median control cells (Figure $1 \mathrm{~A})$. The immunoassay based on cell lysates confirmed that RF but not HAF caused fibroblasts to increas- ingly produce IL11 (Figure 1B). Experiments were also performed with reconstituted regular $(\mathrm{R})$ and hypoallergenic $(\mathrm{H})$ formulas from 3 providers (R1, H1, R2, H2, R3, H3; Figure 1C).

To confirm the activation of TGF- $\beta$ signaling by reconstituted formulas, nuclear translocation of Smad2/3 in oral fibroblasts was determined. Figure 2 shows that RF strongly increased the nuclear staining of Smad2/3, but only weak signals were detected when cells were exposed to HAF. In support of this finding, phosphorylation of Smad3 increased with RF but not with HAF (Figure 3). Moreover, RF lost the capacity to increase NOX 4, PRG4, and IL11 expression when TGF- $\beta$ signaling was blocked by SB431542 (Supplemental Figure S1; https://doi.org/10.3168/jds.2019-18067). To simulate the processing of RF into HAF, we performed proteolytic cleavage with papain, similar to the process for producing whey and casein protein hydrolysates (Gani et al., 2015a,b). As can be seen in Figure 4, RF exposed to papain had an impaired ability to promote the expression of the TGF- $\beta$ target genes $N_{4}, P R G_{4}$, and IL11. The same was observed when recombinant TGF- $\beta 1$ was exposed to papain (data not shown). Taken together, these findings suggest that HAF compared with RF has a negligible TGF- $\beta$ activity. 

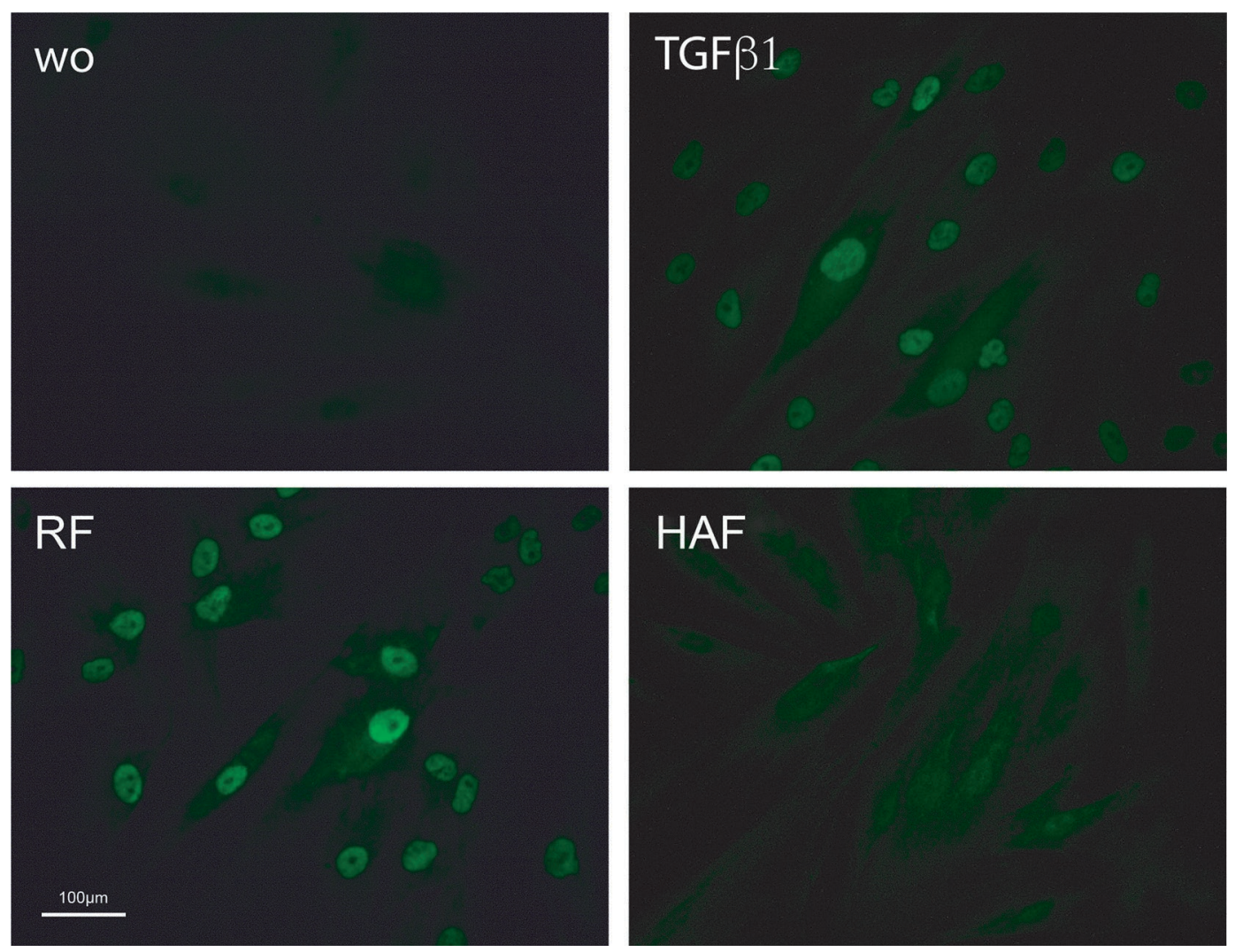

Figure 2. Effect of formula on Smad2/3 nuclear translocation. Serum-starved gingival fibroblasts were exposed to $1 \%$ reconstituted pooled regular infant formula (RF) or 1\% hypoallergenic infant formula (HAF) for $30 \mathrm{~min}$ before fluorescent labeling of Smad2/3. The nuclear signal of Smad2 $/ 3$, indicating activation of TGF- $\beta$ signaling, is visible in cells exposed to recombinant TGF- $\beta$ ( $5 \mathrm{ng} / \mathrm{mL})$ and RF, but not in cells exposed to HAF; wo (without) represents serum-free medium only and was considered the untreated control.

\section{Expression of Inflammatory Cytokines}

Based on our recent observations that regular formula has a clear anti-inflammatory activity in oral gingival

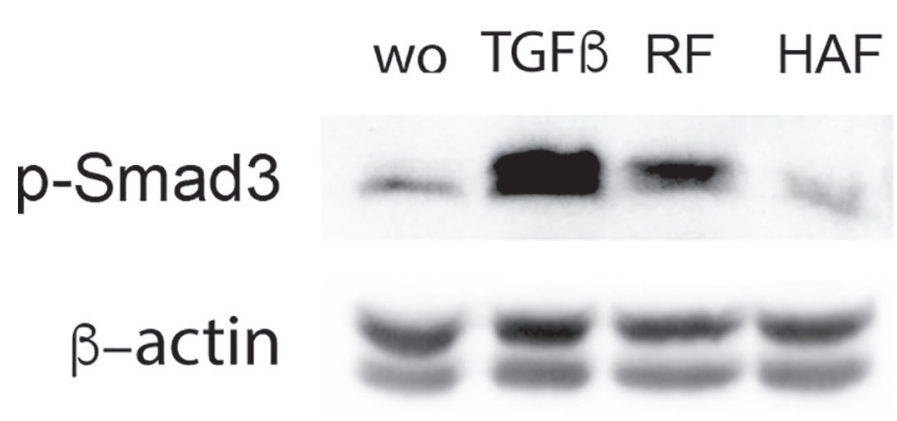

Figure 3. Effect of formula on phosphorylation (p) of Smad-3. Serum-starved gingival fibroblasts were exposed to $1 \%$ reconstituted pooled regular infant formula $(\mathrm{RF})$ or $1 \%$ hypoallergenic infant formula (HAF) for $30 \mathrm{~min}$ before being subjected to Western blot analysis of phosphorylation of Smad- 3 , indicating TGF- $\beta$ signaling. Cells exposed to recombinant TGF- $\beta(5 \mathrm{ng} / \mathrm{mL})$ and $\mathrm{RF}$, but not to HAF, showed a strong increase in the phosphorylation of Smad-3; wo (without) represents serum-free medium only and was considered as our untreated control. fibroblasts (Panahipour et al., 2019), it was reasonable to investigate whether the findings can be reproduced with hypoallergenic formula. We confirm here that $1 \%$ RF greatly suppressed the IL- $1 \beta$ and $T N F \alpha$-induced inflammatory response in gingival fibroblasts. The RF reduced expression of IL-1 and IL-8 to 50.5 and $42.0 \%$ (median values of expression remaining), respectively, compared with $100 \%$ in stimulated controls (Figure $5 \mathrm{~A})$. The HAF had weaker anti-inflammatory activity, as indicated by the reduced expression of IL-1 and IL-8 to $81.5(P=0.11)$ and $71.5 \%(P=0.02 ;$ median values of expression remaining), respectively, compared with stimulated controls (Figure 5A). We next performed p65 immunostaining because its nuclear translocation is a clear sign for activation of the NFkB factor family of transcription factors (Oeckinghaus and Ghosh, 2009). Hence, support for the anti-inflammatory activity of formulas is shown by reduced nuclear translocation of p65 (Figure 6). We then determined the possible reduction in phosphorylation of p38 MAP kinases because they mediate cellular responses to external stress signals, including inflammatory cytokines (Kumar et al., 2003). We observed reduced phosphorylation of p38 

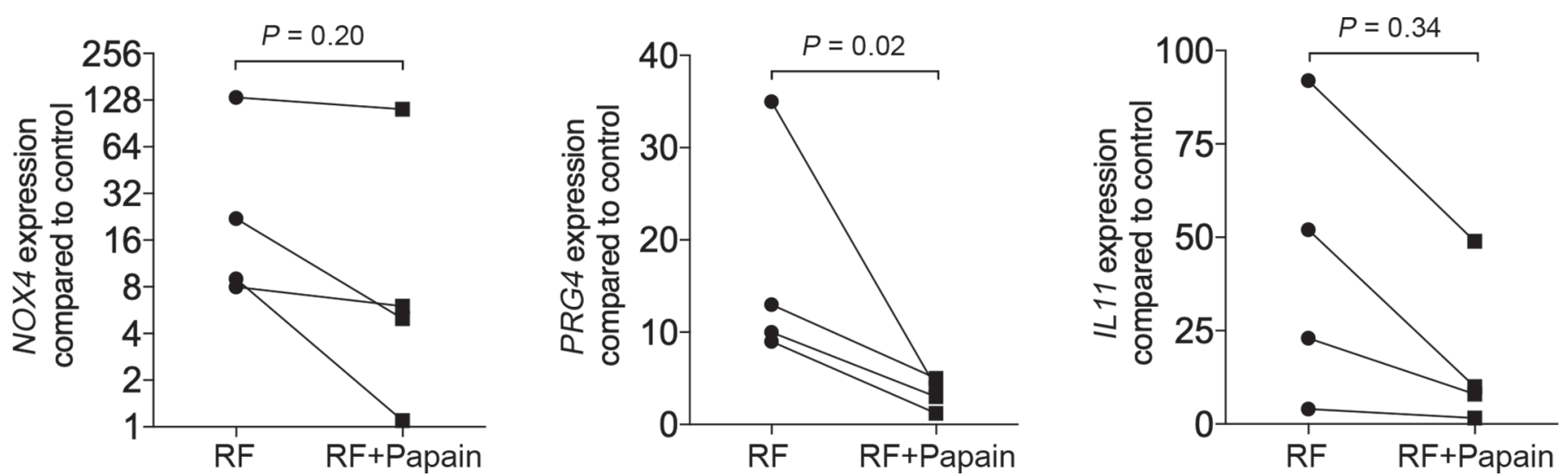

Figure 4. Effect of formula plus papain on TGF- $\beta$ target genes. Gingival fibroblasts were exposed to $1 \%$ reconstituted pooled regular infant formula $(\mathrm{RF})$ or papain-treated $\mathrm{RF}$ for $24 \mathrm{~h}$ followed by analysis of expression of NOX4, PRG4, and IL11. Data points represent independent experiments. Statistical analysis was based on Mann-Whitney U test.

MAP kinases; however, no substantial differences were observed when comparing RF with HAF (Figure 7).

\section{Inflammatory Response in Oral Epithelial Cells}

Following up on our observation with oral squamous cell carcinoma cells (Panahipour et al., 2019), and consistent with the findings observed with oral fibroblasts reported here, $1 \%$ RF significantly inhibited the IL-1 $\beta$ and TNF- $\alpha$-induced expression of inflammatory cytokines in HSC-2 cells, as indicated by the reduced expression of IL-1 and IL-8 by 54.0- and 37.5-fold, respectively, in median compared with stimulated controls (Figure 5B). The HAF also provoked an anti-inflammatory activity; however, it was weaker than that of RF, as shown by the reduced expression of IL-1 and IL- 8 by $77.5(P=0.34)$ and $74.0 \%(P=0.02)$, respectively, compared with a stimulated control (Figure 5B).

\section{Inflammatory Response in Macrophages}

Based on our recent observations that milk has a clear anti-inflammatory activity in primary macrophages (Panahipour et al., 2018a), it was reasonable to investigate whether the findings can be reproduced with RF and HAF. We showed that $1 \%$ RF greatly suppressed the saliva-induced inflammatory response in primary macrophages: RF reduced expression of IL-1 and IL-6, with 35.0 and $21.0 \%$ expression remaining (median values), respectively, compared with $100 \%$ stimulated controls (Figure 5C). Consistent with the overall picture, the HAF had a weaker anti-inflammatory stimulus, as indicated by remaining expression of IL-1 and IL-6 of $71.0(P=0.11)$ and $63.0 \%(P=0.05)$, respectively, in median compared with stimulated controls (Figure 5C). An immunoassay of macrophage lysates confirmed the increase of IL- 1 by saliva and the decrease with RF and, to a lesser extent, HAF (wo: $3.3 \pm 2.3 \mathrm{ng} / \mathrm{mL}$, saliva: $48.6 \pm 37.5 \mathrm{ng} / \mathrm{mL}$, saliva $+\mathrm{RF}: 12.0 \pm 7.0 \mathrm{ng} /$ $\mathrm{mL}$, and saliva + HAF: $23.3 \pm 29.0 \mathrm{ng} / \mathrm{mL}$ ).

\section{DISCUSSION}

Among the key findings of the present research was that commercially available RF, but not HAF increased expression of the TGF- $\beta$ target genes IL11, $N_{1} X_{4}$, and $P R G_{4}$ in oral fibroblasts. We further report here that RF but not HAF increased phosphorylation of Smad3 and nuclear translocation of Smad2/3, both being hallmarks of TGF- $\beta$ signaling (Derynck and Zhang, 2003). Together, these data suggest that commercially available hypoallergenic formulas lack in vitro TGF- $\beta$ activity, which are clearly present in regular formulas. Moreover, based on our previous observations that pasteurized cow milk, including spray-dried milk, has anti-inflammatory activity in vitro (Panahipour et al., 2018a, 2019), we extended these investigations to hypoallergenic formulas. We showed that regular formulas were more potent than hypoallergenic formulas in reducing the expression of pro-inflammatory cytokines in gingival fibroblasts, HSC-2 epithelial cells, and murine bone marrow macrophages. In line with these observations, both formulas reduced the p65 nuclear translocation and phosphorylation of p38 as central signaling mediators controlling inflammation (Kumar et al., 2003; Oeckinghaus and Ghosh, 2009). These data support the assumption that the anti-inflammatory activity of regular formula is affected by proteolysis processing. In sum, our in vitro findings are important as they suggest that hydrolyzed cow milk loses TGF- $\beta$ activity and has reduced anti-inflammatory activity. 
A

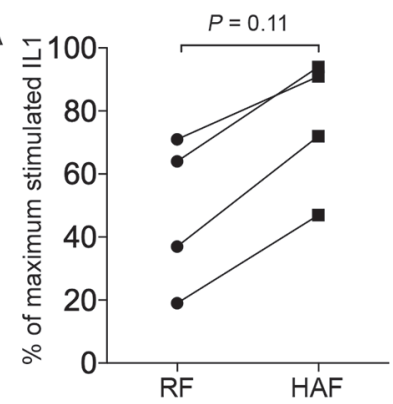

$\mathrm{B}$

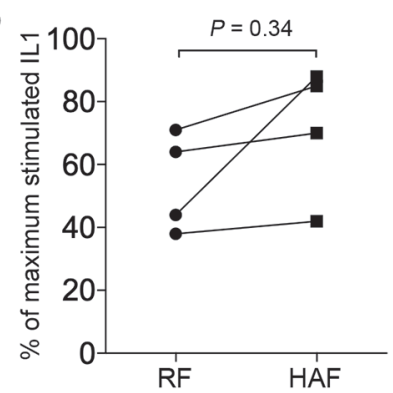

C

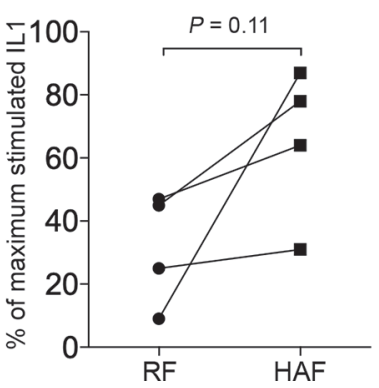

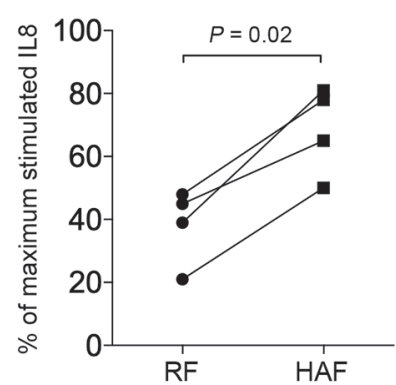
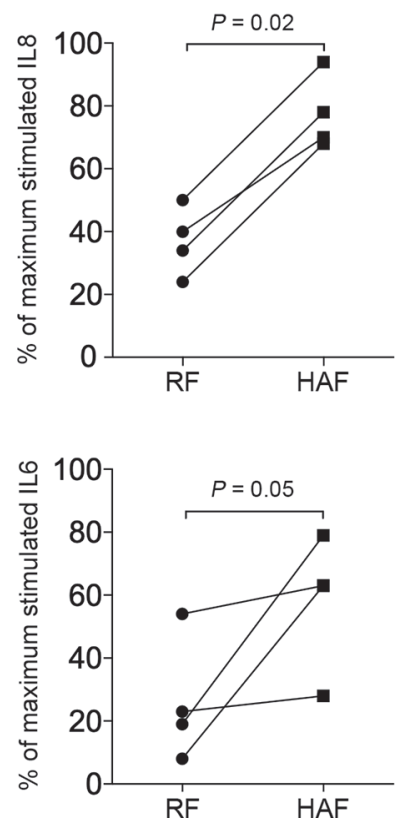

Figure 5. Effect of formula on reducing inflammatory cytokines. Gingival fibroblasts (A) and the oral squamous cell carcinoma cell line HSC-2 (B) were exposed to $1 \%$ reconstituted pooled regular infant formula (RF) or $1 \%$ hypoallergenic infant formula (HAF) in serum-free Dulbecco's modified Eagle medium (DMEM) for $1 \mathrm{~h}$ before adding human IL-1 $\beta$ and TNF- $\alpha$. For murine bone marrow-derived macrophages (C), cytokine expression was stimulated with 5\% sterile human saliva. Expression analysis of IL-1 and IL-8 for gingival fibroblasts and HSC2 cells and expression analysis of IL-1 and IL-6 for macrophages were based on real-time PCR. Data points represent independent experiments. Statistical analysis was based on Mann-Whitney U test.

If we relate our findings to those of others, our data support what is known about milk naturally containing TGF- $\beta$ and that it can exert an anti-inflammatory activity (Okada et al., 1991; Ozawa et al., 2009). However, there is a lack of knowledge with respect to formulas containing TGF- $\beta$, and the anti-inflammatory activity described for formulas requires further confirmation (Panahipour et al., 2019). Our data confirm that regular formula reduces the inflammatory response of gingival fibroblasts exposed to IL- $1 \beta$ and TNF- $\alpha$ (Panahipour et al., 2019). Holvoet et al. (2019) were the first to report that whey protein, but not partially hypoaller-

genic formula, contains TGF- $\beta 2$ activity based on a bioassay. They propose the use of TGF- $\beta$-containing whey protein for supplementation of hydrolyzed formulas. Our observations that formulas lower the inflammatory response of various cell types is novel. These data support the notion that the molecules present in pasteurized milk survive spray drying, suggesting that they are heat stable. However, during the production of hypoallergenic formulas, the anti-inflammatory activity of milk is strongly reduced; thus, the molecules responsible for the anti-inflammatory activity are likely sensitive to proteases but not heating. Therefore, our findings support existing knowledge on regular formulas and indicate that processing milk to achieve hypoallergenic formulas negatively affects TGF- $\beta$ and the antiinflammatory activity in vitro (Holvoet et al., 2019).

The clinical relevance of our findings remains a matter of speculation. In vitro assays that show hypoallergenic formulas negatively affect TGF- $\beta$ and anti-inflammatory activity can only serve as a primer for future preclinical research. This research could involve inflammation models, especially chemically induced colitis (Lara-Villoslada et al., 2006; Ozawa et al., 2009). Moreover, oral administration of commercial cow milk containing TGF- $\beta$ increases the concentration of TGF- $\beta 2$ in human plasma (Ozawa et al., 2009) and gastric acid may be involved in the activation of the latent form of milk TGF- $\beta$ in vivo (Nakamura et al., 2009). In line with this milk research, the oral administration of TGF- $\beta$ increased Smad-responsive reporter activity in the intestines of SBE-luc mice (transgenic mice expressing luciferase in response to activation of the Smad2/3-dependent signaling pathway) and induced Smad2 phosphorylation in the intestines of mice. Serum levels also increased after oral administration of TGF- $\beta$ (Ando et al., 2007). Orally administered high-dose TGF- $\beta$ suppressed serum IgE response and systemic anaphylaxis in a food allergy model (Okamoto et al., 2005). Moreover, Holvoet et al. (2019) reported recently in ovalbumin-tolerized mice, that the TGF- $\beta$-enriched formula but not a hydrolyzed formula reduced allergic reactions, as indicated by total $\mathrm{IgE}$ and mMCP-1 levels. If this reduced allergic reaction is verified, evidence from the oral cavity remains to be elucidated. Moreover, among infants at risk of type 1 diabetes, weaning to a hypoallergenic formula compared with a regular formula has not been shown to reduce the cumulative incidence of type 1 diabetes after median follow-up for 11.5 years (Knip et al., 2018). The present research might be an inspiration to compare regular with hypoallergenic formula in a preclinical setting focused on oral mucositis and colitis, and potentially on aspects related to TGF- $\beta$ activity and inflammation in a clinical setting. 

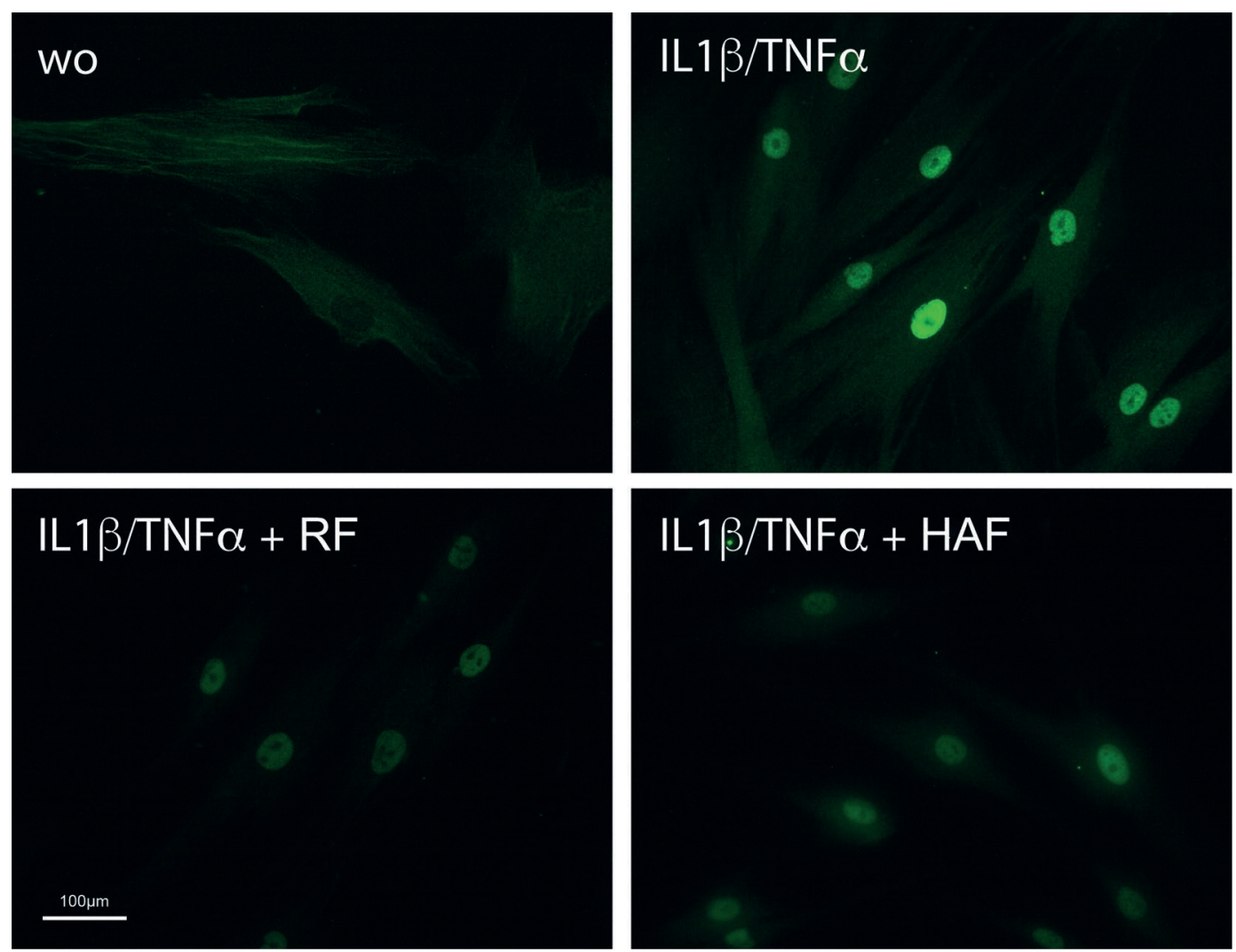

Figure 6. Effect of formula on p65 nuclear translocation. Gingival fibroblasts were exposed to $1 \%$ pooled regular infant formula (RF) or hypoallergenic formulation (HAF) in serum-free Dulbecco's modified Eagle medium (DMEM) for $1 \mathrm{~h}$ before adding human IL-1 $\beta$ and TNF- $\alpha$ for 30 min. The p65 nuclear signal indicating activation of inflammatory nuclear factor-kappa B (NFkB) signaling is visible in cells exposed to IL-1 $\beta$ and TNF- $\alpha$, and with reduced intensity in cells exposed to RF and HAF. The remaining p65 signal may be less intense with RF than with HAF; wo (without) represents serum-free medium only and was considered as our untreated control.

This study has limitations. First, we do not know the role of the proteases on losing the TGF- $\beta$ and anti-inflammatory activity in the course of producing

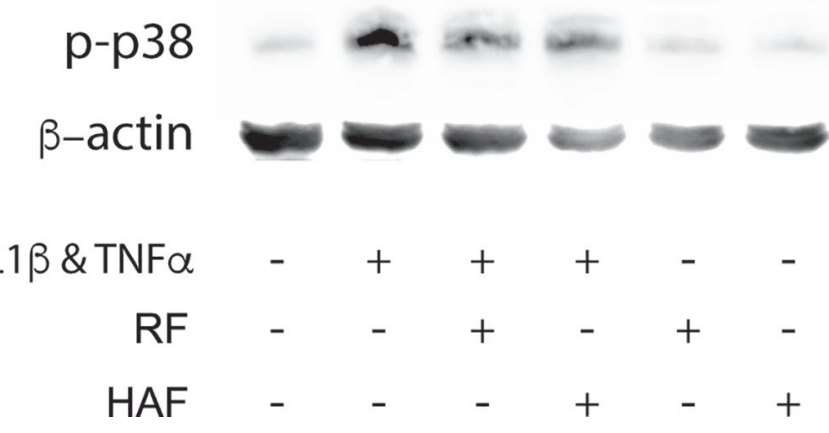

Figure 7. Western blot analysis of phosphorylation (p) of p38, a major intracellular signaling molecule of inflammation, was performed on serum-starved gingival fibroblasts exposed to $1 \%$ reconstituted pooled regular infant formula $(\mathrm{RF})$ or $1 \%$ hypoallergenic infant formula (HAF) for 30 min. Cells stimulated with IL-1 $\beta$ and TNF- $\alpha$ alone showed a robust increase in the phosphorylation of p38 that was attenuated by previous exposure of cells to RF and HAF. the hypoallergenic formula. The procedures on how to produce the hypoallergenic formula are not published by the manufacturer. We can speculate that one of the proteases could be papain, a cysteine protease (Gani et al., 2015a,b). Also, pepsin and trypsin have been successfully used in the production of peptides with antihypertensive properties using milk protein as substrate (Mullallya et al., 1997). Additionally, Danaus plexippus (monarch butterfly) gut peptidases are capable of milk protein hydrolysis. The peptidases hydrolyze caseins and whey proteins, and would be appropriate to prepare infant formulas (Oliveira et al., 2018). It might be the case that not all proteases used to produce hypoallergenic formulas affect TGF- $\beta$ and the anti-inflammatory activity of regular formulas. The molecular and cellular mechanisms on how formula-derived TGF- $\beta$ supports immunity have not yet been established. Evidence is indirect; for example, in infants, TGF- $\beta$ in colostrum may prohibit atopic disease development and lead to IgA production (Kalliomäki et al., 1999); TGF- $\beta$ may also play a critical role in growth and development in infants (Alsharnoubi et al., 2019). A major question 
yet to be answered is which molecules mediate the anti-inflammatory response to milk. It would also be relevant to see the translation of our findings based on commercially available infant formulas in vivo. First insights might be achieved based on the INFOGEST static in vitro simulation of gastrointestinal food digestion (Brodkorb et al., 2019) before preclinical research. In conclusion, our data suggest that the processing of cow milk into hypoallergenic formula negatively affects TGF- $\beta$ and the anti-inflammatory activity in vitro.

\section{ACKNOWLEDGMENTS}

L. P. designed and conducted the research; R. G. designed the research; A. A. T. conducted the research; L. P. and R. G. analyzed data, performed the statistical analysis, wrote the paper, and have primary responsibility for the final content. All authors have read and approved the final manuscript. R. G. receives funding from the Osteology Foundation (Lucerne, Switzerland) and the Austrian Science Foundation (Vienna, Austria). The authors have not stated any conflicts of interest.

\section{REFERENCES}

Alsharnoubi, J., M. Ishaak, S. Elsheikh, and S. Ezzat. 2019. Transforming growth factor beta-1 in human breast milk and its correlation with infants' parameters. Breastfeed. Med. 14:404-407. https: //doi.org/10.1089/bfm.2018.0214.

American Academy of Pediatrics. 2012. Policy Statement: Breastfeeding and the use of human milk. Pediatrics 129:e827-e841. https:// doi.org/10.1542/peds.2011-3552.

Ando, T., K. Hatsushika, M. Wako, T. Ohba, K. Koyama, Y. Ohnuma, R. Katoh, H. Ogawa, K. Okumura, J. Luo, T. Wyss-Coray, and A. Nakao. 2007. Orally administered TGF-beta is biologically active in the intestinal mucosa and enhances oral tolerance. J. Allergy Clin. Immunol. 120:916-923. https://doi.org/10.1016/j.jaci.2007 .05.023.

Annunziata, A., and R. Vecchio. 2011. Functional foods development in the European market: A consumer perspective. J. Funct. Foods 3:223-228. https://doi.org/10.1016/j.jff.2011.03.011.

Bagci Bosi, A. T., K. G. Eriksen, T. Sobko, T. M. Wijnhoven, and J. Breda. 2016. Breastfeeding practices and policies in WHO European Region Member States. Public Health Nutr. 19:753-764. https://doi.org/10.1017/S1368980015001767.

Bai, G., T. D. Hock, N. Logsdon, Y. Zhou, and V. J. Thannickal. 2014. A far-upstream AP-1/Smad binding box regulates human NOX4 promoter activation by transforming growth factor-beta. Gene 540:62-67. https://doi.org/10.1016/j.gene.2014.02.026.

Bellini, F., G. Ricci, D. Remondini, and A. Pession. 2014. Cow's milk allergy (CMA) in children: Identification of allergologic tests predictive of food allergy. Eur. Ann. Allergy Clin. Immunol. 46:100105 .

Bøgh, K. L., V. Barkholt, and C. B. Madsen. 2015. Characterization of the immunogenicity and allergenicity of two cow's milk hydrolysates-A study in Brown Norway rats. Scand. J. Immunol. 81:274-283. https://doi.org/10.1111/sji.12271.

Brodkorb, A., L. Egger, M. Alminger, P. Alvito, R. Assuncao, S. Ballance, T. Bohn, C. Bourlieu-Lacanal, R. Boutrou, F. Carriere, A. Clemente, M. Corredig, D. Dupont, C. Dufour, C. Edwards, M. Golding, S. Karakaya, B. Kirkhus, S. Le Feunteun, U. Lesmes, A. Macierzanka, A. R. Mackie, C. Martins, S. Marze, D. J. McClements, O. Menard, M. Minekus, R. Portmann, C. N. Santos,
I. Souchon, R. P. Singh, G. E. Vegarud, M. S. J. Wickham, W. Weitschies, and I. Recio. 2019. INFOGEST static in vitro simulation of gastrointestinal food digestion. Nat. Protoc. 14:991-1014. https://doi.org/10.1038/s41596-018-0119-1.

Bu, G., Y. Luo, F. Chen, K. Liu, and T. Zhu. 2013. Milk processing as a tool to reduce cow's milk allergenicity: A mini-review. Dairy Sci. Technol. 93:211-223. https://doi.org/10.1007/s13594-013-0113-x.

Bustin, S. A., V. Benes, J. A. Garson, J. Hellemans, J. Huggett, M. Kubista, R. Mueller, T. Nolan, M. W. Pfaffl, G. L. Shipley, J. Vandesompele, and C. T. Wittwer. 2009. The MIQE guidelines: Minimum information for publication of quantitative real-time PCR experiments. Clin. Chem. 55:611-622. https://doi.org/10 .1373/clinchem.2008.112797.

Carvalho, T. S., T. Baumann, and A. Lussi. 2016. In vitro salivary pellicles from adults and children have different protective effects against erosion. Clin. Oral Investig. 20:1973-1979. https://doi .org/10.1007/s00784-015-1703-1.

Cattaneo, A., T. Burmaz, M. Arendt, I. Nilsson, K. Mikiel-Kostyra, I. Kondrate, M. J. Communal, C. Massart, E. Chapin, and M. Fallon. 2010. Protection, promotion and support of breast-feeding in Europe: Progress from 2002 to 2007. Public Health Nutr. 13:751759. https://doi.org/10.1017/S1368980009991844.

Chavez, R. D., G. Coricor, J. Perez, H. S. Seo, and R. Serra. 2017. SOX9 protein is stabilized by TGF-beta and regulates PAPSS2 mRNA expression in chondrocytes. Osteoarthritis Cartilage 25:332-340. https://doi.org/10.1016/j.joca.2016.10.007.

Cheng, K. K., W. B. Goggins, V. W. Lee, and D. R. Thompson. 2008. Risk factors for oral mucositis in children undergoing chemotherapy: A matched case-control study. Oral Oncol. 44:1019-1025. https://doi.org/10.1016/j.oraloncology.2008.01.003.

Derynck, R., and Y. E. Zhang. 2003. Smad-dependent and Smad-independent pathways in TGF-beta family signaling. Nature 425:577584. https://doi.org/10.1038/nature02006.

Elizur, A., N. Rajuan, M. R. Goldberg, M. Leshno, A. Cohen, and Y. Katz. 2012. Natural course and risk factors for persistence of IgEmediated cow's milk allergy. J Pediatr 161:482-487. https://doi .org/10.1016/j.jpeds.2012.02.028.

Frongia, O., and A. R. Bellomo. 2005. Food allergies and intolerance in infants and children. Medico Bambino 24:533-538.

Gani, A., A. A. Broadway, M. Ahmad, B. A. Ashwar, A. A. Wani, S. M. Wani, F. A. Masoodi, and B. S. Khatkar. 2015a. Effect of whey and casein protein hydrolysates on rheological, textural and sensory properties of cookies. J. Food Sci. Technol. 52:5718-5726. https://doi.org/10.1007/s13197-014-1649-3.

Gani, A., A. A. Broadway, F. A. Masoodi, A. A. Wani, S. Maqsood, B. A. Ashwar, A. Shah, S. A. Rather, and A. Gani. 2015b. Enzymatic hydrolysis of whey and casein protein- Effect on functional, rheological, textural and sensory properties of breads. J. Food Sci. Technol. 52:7697-7709. https://doi.org/10.1007/s13197-015-1840 $-1$.

Green Corkins, K., and T. Shurley. 2016. What's in the bottle? A review of infant formulas. Nutr. Clin. Pract. 31:723-729. https:// doi.org/10.1177/0884533616669362.

Hemmati, A. A., A. Larki-Harchegani, S. Shabib, A. Jalali, A. Rezaei, and G. Housmand. 2018. Wound healing property of milk in full thickness wound model of rabbit. Int J Surg. 54:133-140. https:// doi.org/10.1016/j.ijsu.2018.04.030.

Holvoet, S., M. Perrot, N. de Groot, G. Prioult, T. Mikogami, V. Verhasselt, and S. Nutten. 2019. Oral tolerance induction to newly introduced allergen is favored by a transforming growth factor-beta-enriched formula. Nutrients 11:2210. https://doi.org/10.3390/ nu11092210.

Iglesias-Bartolome, R., A. Uchiyama, A. A. Molinolo, L. Abusleme, S. R. Brooks, J. L. Callejas-Valera, D. Edwards, C. Doci, M.-L. Asselin-Labat, M. W. Onaitis, N. M. Moutsopoulos, J. Silvio Gutkind, and M. I. Morasso. 2018. Transcriptional signature primes human oral mucosa for rapid wound healing. Sci. Transl. Med. 10:eaap8798. https://doi.org/10.1126/scitranslmed.aap8798.

Kalliomäki, M., A. Ouwehand, H. Arvilommi, P. Kero, and E. Isolauri. 1999. Transforming growth factor-beta in breast milk: a potential regulator of atopic disease at an early age. J. Allergy Clin. Immu- 
nol. 104:1251-1257. https://doi.org/10.1016/S0091-6749(99)70021 $-7$.

Kerperien, J., D. Veening-Griffioen, T. Wehkamp, B. van Esch, G. A. Hofman, P. Cornelissen, L. Boon, P. V. Jeurink, J. Garssen, L. M. J. Knippels, and L. E. M. Willemsen. 2018. IL-10 receptor or TGF-beta neutralization abrogates the protective effect of a specific nondigestible oligosaccharide mixture in cow-milk-allergic mice. J. Nutr. 148:1372-1379. https://doi.org/10.1093/jn/nxy104.

Knip, M., H. K. Åkerblom, E. Al Taji, D. Becker, J. Bruining, L. Castano, T. Danne, C. de Beaufort, H.-M. Dosch, J. Dupre, W. D. Fraser, N. Howard, J. Ilonen, D. Konrad, O. Kordonouri, J. P. Krischer, M. L. Lawson, J. Ludvigsson, L. Madacsy, J. L. Mahon, A. Ormisson, J. P. Palmer, P. Pozzilli, E. Savilahti, M. SerranoRios, M. Songini, S. Taback, O. Vaarala, N. H. White, S. M. Virtanen, R. Wasikowa; Writing Group for the TRIGR Study Group. 2018. Effect of hydrolyzed infant formula vs conventional formula on risk of type 1 diabetes: The TRIGR randomized clinical trial. JAMA 319:38-48. https://doi.org/10.1001/jama.2017.19826.

Kumar, S., J. Boehm, and J. C. Lee. 2003. p38 MAP kinases: Key signalling molecules as therapeutic targets for inflammatory diseases. Nat. Rev. Drug Discov. 2:717-726. https://doi.org/10.1038/ nrd1177.

Lalla, R. V., D. P. Saunders, and D. E. Peterson. 2014. Chemotherapy or radiation-induced oral mucositis. Dent. Clin. North Am. 58:341-349. https://doi.org/10.1016/j.cden.2013.12.005.

Lara-Villoslada, F., E. Debras, A. Nieto, A. Concha, J. Galvez, E. Lopez-Huertas, J. Boza, C. Obled, and J. Xaus. 2006. Oligosaccharides isolated from goat milk reduce intestinal inflammation in a rat model of dextran sodium sulfate-induced colitis. Clin. Nutr. 25:477-488. https://doi.org/10.1016/j.clnu.2005.11.004.

Manconi, B., T. Cabras, E. Pisano, M. T. Sanna, A. Olianas, V. Fanos, G. Faa, S. Nemolato, F. Iavarone, M. Castagnola, and I. Messana. 2013. Modifications of the acidic soluble salivary proteome in human children from birth to the age of 48 months investigated by a top-down HPLC-ESI-MS platform. J. Proteomics 91:536-543. https://doi.org/10.1016/j.jprot.2013.08.009.

Monaci, L., V. Tregoat, A. J. van Hengel, and E. Anklam. 2006. Milk allergens, their characteristics and their detection in food: A review. Eur. Food Res. Technol. 223:149-179. https://doi.org/10 $.1007 / \mathrm{s} 00217-005-0178-8$.

Mullallya, M. M., H. Meisel, and R. J. FitzGerald. 1997. AngiotensinI-converting enzyme inhibitory activities of gastric and pancreatic proteinase digests of whey proteins. Int. Dairy J. 7:299-303. https: //doi.org/10.1016/S0958-6946(97)00018-6.

Nakamura, Y., M. Miyata, T. Ando, N. Shimokawa, Y. Ohnuma, R. Katoh, H. Ogawa, K. Okumura, and A. Nakao. 2009. The latent form of transforming growth factor-beta administered orally is activated by gastric acid in mice. J. Nutr. 139:1463-1468. https:// doi.org/10.3945/jn.109.108761.

Oeckinghaus, A., and S. Ghosh. 2009. The NF- $\kappa$ B family of transcription factors and its regulation. Cold Spring Harb. Perspect. Biol. 1:a000034. https://doi.org/10.1101/cshperspect.a000034.

Okada, M., E. Ohmura, Y. Kamiya, H. Murakami, N. Onoda, M. Iwashita, K. Wakai, T. Tsushima, and K. Shizume. 1991. Transforming growth factor (TGF)-alpha in human milk. Life Sci. 48:1151-1156. https://doi.org/10.1016/0024-3205(91)90452-H.

Okamoto, A., T. Kawamura, K. Kanbe, Y. Kanamaru, H. Ogawa, K. Okumura, and A. Nakao. 2005. Suppression of serum IgE response and systemic anaphylaxis in a food allergy model by orally administered high-dose TGF-beta. Int. Immunol. 17:705-712. https:// doi.org/10.1093/intimm/dxh250.

Oliveira, J. P. B., M. V. Ramos, F. E. S. Lopes, I. C. Studart, J. S. Oliveira, M. D. P. Lobo, A. C. O. Monteiro-Moreira, and C. D. T. Freitas. 2018. Gut peptidases from a specialist herbivore of latex plants are capable of milk protein hydrolysis: Inputs for hypoallergenic milk formulas. Food Chem. 255:260-267. https://doi.org/ 10.1016/j.foodchem.2018.02.032.

Osborn, D. A., and J. Sinn. 2006. Formulas containing hydrolysed protein for prevention of allergy and food intolerance in infants. Co- chrane Database Syst. Rev. CD003664. https://doi.org/10.1002/ 14651858.CD003664.pub2.

Osborn, D. A., J. K. Sinn, and L. J. Jones. 2018. Infant formulas containing hydrolysed protein for prevention of allergic disease. Cochrane Database Syst. Rev. 10:CD003664. https://doi.org/10 .1002/14651858.CD003664.pub6.

Ozawa, T., M. Miyata, M. Nishimura, T. Ando, Y. Ouyang, T. Ohba, N. Shimokawa, Y. Ohnuma, R. Katoh, H. Ogawa, and A. Nakao. 2009. Transforming growth factor-beta activity in commercially available pasteurized cow milk provides protection against inflammation in mice. J. Nutr. 139:69-75. https://doi.org/10.3945/jn .108 .092528

Panahipour, L., E. Kochergina, A. Kreissl, N. Haiden, and R. Gruber. 2018a. Milk modulates macrophage polarization in vitro. Cytokine: X 1:100009.

Panahipour, L., S. Nasserzare, Z. Amer, F. Brucke, A. Stahli, A. Kreissl, N. Haiden, and R. Gruber. 2019. The anti-inflammatory effect of milk and dairy products on periodontal cells: An in vitro approach. Clin. Oral Investig. 23:1959-1966. https://doi.org/10 .1007/s00784-018-2642-4.

Panahipour, L., A. Stahli, N. Haiden, and R. Gruber. 2018b. TGFbeta activity in cow milk and fermented milk products: An in vitro bioassay with oral fibroblasts. Arch. Oral Biol. 95:15-21. https:// doi.org/10.1016/j.archoralbio.2018.07.005.

Pourgonabadi, S., H. D. Muller, J. R. Mendes, and R. Gruber. 2017. Saliva initiates the formation of pro-inflammatory macrophages in vitro. Arch. Oral Biol. 73:295-301. https://doi.org/10.1016/j archoralbio.2016.10.012

Sackesen, C., A. Assa'ad, C. Baena-Cagnani, M. Ebisawa, A. Fiocchi, R. G. Heine, A. Von Berg, and O. Kalayci. 2011. Cow's milk allergy as a global challenge. Curr. Opin. Allergy Clin. Immunol. 11:243-248. https://doi.org/10.1097/ACI.0b013e328346566f.

Schmittgen, T. D., and K. J. Livak. 2008. Analyzing real-time PCR data by the comparative C(T) method. Nat. Protoc. 3:1101-1108. https://doi.org/10.1038/nprot.2008.73.

Sicherer, S. H., and H. A. Sampson. 2014. Food allergy: Epidemiology, pathogenesis, diagnosis, and treatment. J. Allergy Clin. Immunol. 133:291-307. https://doi.org/10.1016/j.jaci.2013.11.020.

Sitarik, A. R., K. R. Bobbitt, S. L. Havstad, K. E. Fujimura, A. M. Levin, E. M. Zoratti, H. Kim, K. J. Woodcroft, G. Wegienka, D. R. Ownby, C. L. M. Joseph, S. V. Lynch, and C. C. Johnson. 2017. Breast milk transforming growth factor beta is associated with neonatal gut microbial composition. J. Pediatr. Gastroenterol. Nutr. 65:e60-e67. https://doi.org/10.1097/MPG.0000000000001585.

von Berg, A., B. Filipiak-Pittroff, U. Kramer, E. Link, J. Heinrich, S. Koletzko, A. Grubl, U. Hoffmann, C. Beckmann, D. Reinhardt, C. P. Bauer, E. Wichmann, and D. Berdel. 2017. The German Infant Nutritional Intervention Study (GINI) for the preventive effect of hydrolyzed infant formulas in infants at high risk for allergic diseases. Design and selected results. Allergol Select 1:28-39. https:/ /doi.org/10.5414/ALX01462E.

Zhang, X., H. Wu, J. R. Dobson, G. Browne, D. Hong, J. Akech, L. R. Languino, G. S. Stein, and J. B. Lian. 2015. Expression of the IL-11 gene in metastatic cells is supported by Runx2-Smad and Runx2-cJun complexes induced by TGFbeta1. J. Cell. Biochem. 116:2098-2108. https://doi.org/10.1002/jcb.25167.

Zwiebel, J. A., M. Bano, E. Nexo, D. S. Salomon, and W. R. Kidwell. 1986. Partial purification of transforming growth factors from human milk. Cancer Res. 46:933-939.

\section{ORCIDS}

Layla Panahipour @ https://orcid.org/0000-0003-3557-3493 Amirali Abooneghab Tabatabaei $\odot$ https://orcid.org/0000-0002-8090 $-8857$

Reinhard Gruber () https://orcid.org/0000-0001-5400-9009 